\title{
ESTUDOS COMPARATIVOS DOS RECURSOS DE POLIDEZ NA LÍNGUA JAPONESA E NA LÍNGUA PORTUGUESA
}

Satomi Oishi Azuma

Resumo: Este artigo é baseado num questionário-piloto sobre os recursos de polidez na língua japonesa e na língua portuguesa falada em Curitiba, aplicados em expatriados japoneses com menos de três anos no Brasil e em brasileiros, funcionários de empresas instaladas em Curitiba. Pretendemos fazer um levantamento das estratégias de polidez dos falantes para classificar, analisar e verificar as diferenças e o grau de polidez das duas línguas.

Palavras-chave: polidez, língua japonesa, língua portuguesa, estratégias

\begin{abstract}
This article is based on a pilot questionnaire about the features of politeness in Japanese and Portuguese language spoken in Curitiba which was applied to Japanese expatriates with less than three years in Brazil and for Brazilian corporate employees. We intend to make a survey of politeness strategies used by speakers in order to classify, analyze and verify the differences and the degree of politeness of both languages.
\end{abstract}

Keywords: Politeness, Japanese language, Portuguese language, strategies

\section{Introdução}

As pessoas se utilizam de várias estratégias para se comunicar. Brown e Levinson (1987) constataram que havia certa universalidade da polidez como um fator regulador das trocas conversacionais e pregam que o falante tende a manter a sua imagem através das estratégias verbais e não verbais para evitar os efeitos negativos e preservar a autoimagem pública, respeitando a imagem do interlocutor.

1. Satomi Oishi Azuma, mestranda UFPR, área - Linguística, professora auxiliar de Língua Japonesa na Universidade Federal do Paraná, satomiazuma@gmail.com 
Há um mito de que a língua japonesa é extremamente polida em todos os níveis e o português é muito mais informal, por isso os estudantes de Japonês como língua estrangeira (doravante JL2) encontram maior dificuldade para compreender e usar as expressões de tratamento. No entanto, a pesquisadora tem percebido que em certos contextos, a polidez no português é tão presente quanto na língua japonesa, mas com estratégias diferentes.

Para comprovar esta hipótese, foi entregue a seis falantes nativos de língua japonesa (funcionários de empresas japonesas ou funcionário de representação japonesa em Curitiba, que estudam o português em Curitiba) um questionário com três perguntas cada qual num contexto diferente em que os honoríficos seriam utilizados ou não. Este foi traduzido em português e entregue a curitibanos, funcionários de empresas privadas da mesma faixa etária. O questionário foi elaborado baseando em dois contextos em que os honoríficos são mais exigidos na língua japonesa e num contexto em que a informalidade estaria mais presente.

Com esses dados, pretende-se fazer um levantamento das estratégias usadas pelos falantes das duas línguas e fazer um comparativo.

Este artigo foi baseado neste questionário piloto que visa verificar a aplicabilidade ou não do estudo.

\section{Princípio de cooperação e a teoria da polidez}

A aprendizagem de língua japonesa como língua estrangeira tem sido objeto de muitas pesquisas pelos estudiosos da linguística aplicada. As expressões de tratamento na língua japonesa sempre foram e são um dos tópicos mais complicados para um estudante estrangeiro apreender o seu mecanismo de uso devido a sua complexidade gramatical e principalmente por envolver fatores sociolinguísticos e pragmáticos. Por ser uma língua milenar, usada num ambiente onde a hierarquia esteve sempre presente, a língua japonesa é estruturada baseada nos princípios da hierarquia.

Além disso, há o fator interioridade/exterioridade (explicado com maiores detalhes no capítulo 3, HONORÍFICOS) que exige também o uso das expressões de tratamento. Atualmente este é o fator que faz o falante mais aplicar os honoríficos, superando a hierarquia. A teoria da polidez de Brown e Levinson (1987) pode contribuir para a melhor compreensão do uso dessas expressões de tratamento. Para melhor ilustrar os atos de fala, abaixo passaremos a apresentar as teorias de Grice, e de Brown e Levinson.

O princípio de cooperação (PCO) postulado por Grice $(1975,1978)$ é um dos fundamentos da teoria da polidez no âmbito da pragmática. É ele que guia a interação verbal. Os usuários da língua se cooperam mutuamente para que a 
comunicação aconteça da melhor forma possível. As máximas conversacionais que regem o PCO de Grice são:

- Máxima de Quantidade: Diga somente o necessário.

- Máxima de Qualidade: Seja sincero, não diga nada que você acredite ser falso ou não diga nada que não haja prova suficiente;

- Máxima da relevância: seja relevante

- Máxima de modo: seja claro. Evite ambiguidade; seja breve e ordenado.

Grice $(1975,1978)$ sinaliza também que há outras máximas de caráter estético, social ou moral, como 'seja polido', que são seguidas pelos que participam da conversação. $\mathrm{O}$ autor esclarece que há diferença entre as línguas naturais e as línguas artificiais. As línguas naturais podem apresentar elementos que não estão de acordo com a verdade, o que leva à implicatura, ou seja, a inferência que os participantes de uma conversação fazem com base no enunciado e na relação entre o enunciado e os elementos situacionais e não verbais. Na comunicação, muitas vezes nós implicamos, isto é, acrescentamos outros significados ao que realmente 'é dito' e cabe ao interlocutor fazer cálculos e descobrir a implicatura, o significado por trás da mensagem. O Princípio de Cooperação de Grice $(1975,1978)$ foi essencial no desenvolvimento da pesquisa da polidez, pois as implicaturas conversacionais e o fenômeno da polidez foram observados devido a não obediência às máximas griceanas. Convém ressaltar que a noção de "polidez" aqui mencionada é a do sentido amplo, que encobre todos os aspectos do discurso que são regidos por regras que têm como objetivo preservar o caráter harmonioso da relação interpessoal. Não é a "polidez" dos manuais de convivência social e das etiquetas.

O modelo de polidez de Brown e Levinson (1987) tenta complementar o PCO de Grice e ampliar o modelo da imagem social postulado por Goffman (1967). Brown e Levinson (1987) formulam a teoria da imagem/face baseada nas teorias acima citadas.

A imagem ou face apresenta dois lados:

- imagem negativa - o desejo do falante de que suas ações não sejam impedidas e não sofram imposições, em outros termos, ter o seu território respeitado; - imagem positiva - o desejo do falante de ser aprovado por outros interlocutores e ter seus desejos compartilhados por outra pessoa.

Para os autores acima citados, a polidez nas interações é usada para salvar as duas faces, dando origem à polidez negativa e à polidez positiva. A polidez negativa consiste em evitar o confronto e o conflito e a polidez positiva busca a aproximação e a solidariedade. A teoria da polidez proposta pelos linguistas 
Brown e Levinson (1987 [1978]) oferece ferramentas teóricas e descritivas para a compreensão das estratégias de polidez utilizadas pelo falante para alcançar seus objetivos promovendo e mantendo uma relação harmoniosa. Essas estratégias incluem interrogações, as modalidades verbais, as expressões de tratamento e outros. Existem também as estratégias totalmente diretas, como o uso da forma imperativa em situação de emergência, ou quando o poder social do falante é superior ao do ouvinte, como no caso do diretor para a sua secretária: "Entregue já este relatório para o departamento financeiro." Há também as estratégias chamadas off record (totalmente indireta como metáforas, ironias, etc.)

Com o estudo e observação de estratégias linguísticas empregadas por falantes de três línguas diferentes - o inglês da Inglaterra, o tâmil (língua falada no sul da Índia) e o tzeltal (língua mais falada na comunidade de Tenejapa, no México) - de diferentes continentes, de diferentes sociedades e culturas, Brown e Levinson constataram que havia certa universalidade na polidez como um fator regulador das trocas conversacionais e elaboraram a teoria da polidez. Esta suposta universalidade tem suscitado diversas discussões principalmente nas línguas usadas pelas culturas, onde a deferência é de uso obrigatório como a japonesa e a coreana. A princípio, esta teoria foi muito criticada pelos linguistas japoneses, como Matsumoto e Ide, que afirmavam que a universalidade não poderia ser aplicada às línguas em que não prevalece a vontade do falante e que o controle na fala, como os honoríficos, é utilizado pela força da cultura social.

Cada língua possui características próprias e tendências relacionadas aos recursos utilizados para fazer o seu discurso. Segundo Chinami (2005), as estratégias usadas para preservar as faces propostas por Brown e Levinson(1987) também são utilizadas na língua japonesa.

Chinami cita que é de conhecimento geral que o keigo, os honorífico japoneses, já foi citado como equivalente à face negativa institucionalizada. Existem regras para o uso dos honoríficos, mas elas não são fixas, possibilitando a opção de uso e interpretação conforme o contexto e a vontade do locutor.

Para melhor compreender o que representa os honoríficos na língua japonesa, no item seguinte, serão apresentados a função básica e o seu uso normativo.

\section{Os honoríficos japoneses}

Os honoríficos na língua japonesa são usados constantemente nos atos de fala em diversos níveis e há uma normatização do seu uso.

Segundo Takiura (2005), no início do século 17, o jesuíta João Rodriguez que esteve no Japão por quarenta anos como missionário, cita na Arte da Lingoa de Iapam, obra publicada pelo Seminário de Nagasaki, que na língua japonesa há verbos próprios de respeito que são usados na segunda e na terceira pessoa e ou- 
tros verbos próprios para o falante, que através do seu uso, demonstra humildade para com o interlocutor. Essas palavras são dirigidas com respeito para o interlocutor ou para com as pessoas presentes no ato de fala - referente. Nos verbos que expressam ações da pessoa do falante ou para se referir a si mesmo são usadas formas de depreciação.

Esta percepção de falante/interlocutor/referente tão difundida atualmente já foi constatada no estudo da língua japonesa por um estudioso português no início do século 17 e observado também por um professor inglês, Chamberlain em 1888/1889 na Era Meiji, após a abertura dos portos japoneses que proporcionou a aproximação com a cultura ocidental. Segundo Takiura (2005) há um vácuo de quase 300 anos entre os dois estudos, no entanto, os dois analisaram o japonês com a visão antropológica que vê a sociedade como um todo e percebe não só o sistema de hierarquia presente nela como ele reflete na língua falada. Eles souberam também identificar os três elementos essenciais para a realização do ato de fala da língua japonesa, que seriam - quem fala, para quem e de que/de quem se fala. Os teóricos japoneses que infelizmente não tiveram acesso às obras de Rodriguez, uma vez que o Japão ficou isolado quase três séculos do Ocidente e essas obras ficaram fora do alcance deles, só chegam a essa conclusão no final do século 19 e início do século 20.

Tae Suzuki (1995, p. 15) cita em As expressões de tratamento da língua japonesa que as expressões de tratamento carregam valores socioculturais próprios que resultam num complexo de relações entre indivíduo e meio, entre meio e visão de mundo, entre indivíduo e recorte da realidade. Os honoríficos da língua japonesa apresentam formas de se expressar distintas daquelas mais comuns nas línguas ocidentais.

Para melhor entender as expressões de tratamento, a seguir serão apresentadas as relações sociais da sociedade japonesa, que são regidas por dois eixos: o eixo horizontal e o eixo vertical.

Segundo Kikuchi (2011, p. 198), fatores como interioridade/exterioridade ${ }^{2}$, afinidade e interesses comuns e subjetividade são encontrados em outras sociedades, mas eles interferem com maior intensidade na interação entre os japoneses, constituindo a dicotomia círculo interno versus círculo externo. O círculo interno é formado por familiares e parentes, colegas, superiores da empresa, ou seja, por todos os membros do grupo ou instituição ou aliados com quem tem afinidades e interesses comuns. Nessa classificação, são incluídos os pertences, os sentimentos e opiniões dessas pessoas. Por outro lado, todos aqueles que não fazem parte do círculo interno, são considerados do círculo externo. "Essa visão dicotômica classifica o mundo em "os de dentro" e "os de fora" em todos os aspectos da vida,

2. Uchi/soto foi traduzido para português como interioridade/exterioridade por Suzuki (1995, p. 22). 
tanto na vida privada como na vida profissional, no nível material ou imaterial, real ou virtual." (Kikuchi, 2011, p. 199). Convém lembrar que é tradição no Japão, o emprego ser para a vida toda, por isso o espírito de pertencimento à empresa é muito grande.

Por outro lado, o eixo vertical representa a hierarquia existente na sociedade, que estabelece as posições de superior e inferior, sendo alguns atribuídos e outros adquiridos. A questão hierárquica envolve classes sociais e status, cargos e papéis sociais, antiguidade e ordem de ingresso no meio, idade, sexo e competência.

Baseando nesses dois eixos, o falante faz a opção de qual expressão de tratamento ele deve usar. No círculo interno, sobretudo dentro da família, há a predominância de linguagem informal, desprovida de cordialidade e de expressões de respeito ou de modéstia. Dentro da empresa, embora haja a hierarquia, o grau de cordialidade e respeito é menor do que com a interação com alguém do círculo externo.

O falante usará os termos de modéstia para ele próprio e para todos os membros do seu grupo e os termos de respeito para todos aqueles que não pertençam ao seu grupo.

\section{Classificação das expressões de tratamento}

Para Suzuki (1995), as formas de tratamento da língua japonesa podem ser classificadas como:

Tratamento do enunciado: que estabelece e determina a distância que o locutor assim conclui existir entre as pessoas do enunciado, depois de ponderar os fatores extralinguísticos relevantes que as definem num contexto de situação, elevando ou rebaixando os inferiores.

Tratamento da enunciação: que traduz a atenção do destinador do discurso em se endereçar polidamente ao destinatário, independentemente da relação de forças existentes entre eles. (SUZUKI, 1995, p. 20)

Ainda utilizando as explicações de Suzuki, o tratamento do enunciado seria a mensagem em si, considerando os fatores extralinguísticos como sexo, status sociais etc. No enunciado, cabe ao locutor expressar uma mesma deferência por alguém que ele considera superior a si ou a outra pessoa em um dado contexto, usando as expressões de respeito e de modéstia. (SUZUKI, 1995, p. 20)

A palavra keigo que se escreve usando os dois ideogramas, 敬語, é uma composição de 敬 (kei) - respeito, 語 (go - a palavra/língua, ou seja, a palavra/ língua de respeito, keigo, são os honoríficos propriamente ditos. Ele é subdivido em duas formas: 尊敬語 - sonkeigo (尊敬 - respeito, 語 - palavra/expressão), e 謙譲語 - kenjôgo (謙讓 - humildade, 語 - palavra/expressão). O primeiro 
é usado com deferência pelo falante para o interlocutor ou sobre o referente e o segundo quando o falante se refere a si mesmo ou a seu grupo com humildade para o interlocutor. Usando os termos de humildade para si, ele demonstra respeito ao interlocutor. Vejamos o exemplo abaixo:

(1) Shachô(wa) irasshaimasuka. (o presidente está?)

(2) Hai, Shachô(wa) orimasu. (o presidente está.)

No exemplo (1), o falante está usando o sonkeigo, honorífico de respeito, que pode ser usado dirigindo para alguém do grupo externo ou ainda para perguntar a um colega se o presidente da empresa está. No exemplo (2), o falante está usando o kenjôgo, honorífico de humildade. $\mathrm{O}$ falante pode estar comunicando ao interlocutor externo que o presidente está na empresa, ou ainda comunicar ao interlocutor da própria empresa que o presidente, hierarquicamente superior ao falante e ao interlocutor, está na empresa.

Tanto o sonkeigo como o kenjôgo sofrem alterações lexicais e gramaticais na sua formação, conforme tabela abaixo:

Tabela 1 - Classificação do keigo, honoríficos.

\begin{tabular}{|c|c|c|c|c|c|}
\hline $\begin{array}{l}\text { Classe } \\
\text { gramatical }\end{array}$ & $\begin{array}{l}\text { Significado } \\
\text { em português }\end{array}$ & $\begin{array}{l}\text { Neutro/ } \\
\text { forma plana }\end{array}$ & Sonkeigo & Kenjôgo & Observação \\
\hline \multirow[t]{4}{*}{ Substantivo } & Nome & Namae & $\begin{array}{l}\text { Onamae } \\
\text { Acréscimo do } \\
\text { prefixo O }\end{array}$ & namae & \multirow{2}{*}{$\begin{array}{l}\text { Os prefixos "O" } \\
\text { e "GO" são } \\
\text { usados de } \\
\text { acordo com a } \\
\text { origem da } \\
\text { palavra. } \\
\text { Geralmente se } \\
\text { for japonesa se } \\
\text { usa "O" e se for } \\
\text { chinesa "GO". }\end{array}$} \\
\hline & Endereço & Jûsho & $\begin{array}{l}\text { Gojûsho } \\
\text { Acréscimo do } \\
\text { prefixo GO }\end{array}$ & jûsho & \\
\hline & Tanaka & Tanaka & $\begin{array}{l}\text { Tanakasan } \\
\text { Acréscimo do } \\
\text { sufixo SAN }\end{array}$ & Tanaka & \\
\hline & Pai & Chichi & Otôsan & Chichi & $\begin{array}{l}\text { Formação } \\
\text { específica }^{4}\end{array}$ \\
\hline Pronome & $\begin{array}{l}\text { Vossa } \\
\text { senhoria/ } \\
\text { sua empresa }\end{array}$ & Kaisha & Kiden & Heisha & $\begin{array}{l}\text { Formação } \\
\text { específica }\end{array}$ \\
\hline
\end{tabular}

3. Neste trabalho, nos exemplos, as partículas estarão entre parênteses.

4. Formação específica - Indica a expressão de tratamento específica para o léxico, termo usado em de Kikuchi, 2011, p. 205. 


\begin{tabular}{|c|c|c|c|c|c|}
\hline \multirow[t]{2}{*}{ Adjetivo } & Gentil & Shinsetu & Goshinsetsu & Goshinsentsu & $\begin{array}{l}\text { Segue a mesma } \\
\text { regra do } \\
\text { substantivo } \\
\text { (vide acima) }\end{array}$ \\
\hline & Saudável & Genki & Ogenki & Ogenki & \\
\hline \multirow[t]{2}{*}{ Verbos } & Escrever & Kaku & $\begin{array}{l}\text { OkakiNINARU } \\
\text { Acréscimo do } \\
\text { prefixo } O \mathrm{e} \\
\sim N I N A R U\end{array}$ & $\begin{array}{l}\text { OkakiSURU } \\
\text { OkakiITASU }\end{array}$ & $\begin{array}{l}\text { Os verbos que } \\
\text { não possuem } \\
\text { formas } \\
\text { específicas } \\
\text { para os }\end{array}$ \\
\hline & & Kaku & $\begin{array}{l}\text { KakaRERU } \\
\text { Acrescimo do } \\
\sim R E R U \\
\text { (terminação } \\
\text { da voz passiva) }\end{array}$ & $\begin{array}{l}\text { Acréscimo do } \\
\text { prefixo } O \\
\text { e verbo } \\
\sim S U R U \text { ou } \\
\sim I T A S U\end{array}$ & $\begin{array}{l}\text { honoríficos } \\
\text { de respeito } \\
\text { possuem duas } \\
\text { formas como } \\
\text { neste exemplo. }\end{array}$ \\
\hline \multirow[t]{5}{*}{ Verbos } & Ver & Miru & Goran ni naru & Haiken suru & $\begin{array}{l}\text { Formação } \\
\text { específica }\end{array}$ \\
\hline & Ir & Iku & Irassharu & Mairu & $\begin{array}{l}\text { Formação } \\
\text { específica }\end{array}$ \\
\hline & Fazer & Suru & Nasaru & Itasu & $\begin{array}{l}\text { Formação } \\
\text { específica }\end{array}$ \\
\hline & $\begin{array}{l}\text { Comer/ } \\
\text { beber }\end{array}$ & $\begin{array}{l}\text { Taberu/ } \\
\text { nоти }\end{array}$ & Meshiagaru & Itadaku & $\begin{array}{l}\text { Formação } \\
\text { específica }\end{array}$ \\
\hline & Saber & Shiru & Gozonji & Zonjiru & $\begin{array}{l}\text { Formação } \\
\text { específica }\end{array}$ \\
\hline
\end{tabular}

Basil Chamberlain (apud Suzuki, 1995) considerou o kenjôgo equivalente à primeira pessoa e o sonkeigo à segunda e terceira pessoas. Alguns teóricos, japoneses como Yamada (apud Suzuki, 1995) seguiram esta teoria baseada na pessoalidade do tratamento. No entanto, segundo Suzuki, Yamada restringiu sua análise às implicações pessoais que possa haver no enunciado, não estendendo às implicações entre os interlocutores no ato da enunciação.

O tratamento da enunciação, de acordo com Suzuki (1995), são as formas linguísticas empregadas pelo locutor no enunciado, mas como a função precípua de atuar no ato da enunciação, expressando a maneira polida do locutor ao se dirigir ao interlocutor na qualidade de simples destinatário do discurso.

No enunciado, o locutor analisa os fatores extralinguísticos e a posição do interlocutor para formular a mensagem, e, na enunciação, acrescenta ou não os sufixos -desu/-masu, que indica o 丁寜語, teineigo, expressão de "polidez"5, que segundo Suzuki (1995) expressa a maneira cordial do locutor ao se dirigir ao interlocutor na qualidade de simples destinatário do discurso.

5. Termo usado por Suzuki (1995, p. 19). Doravante, este termo para não ser confundido com a "polidez" de Brown e Levinson será grafado em itálico e entre aspas - "polidez". 
Por exemplo, no caso em que um aluno for falar "vou à casa do professor Tanaka". Um falante japonês precisa levar em conta os seguintes aspectos:

a. "Eu" (aluno) inferior ao professor [aluno < professor $]^{6}$;

b. Quem pratica a ação de "ir" é o aluno, assim é necessário considerar que [aluno < professor];

c. A posse é do professor, e a relação é [professor >aluno] ${ }^{7}$. No japonês, em geral, o pronome pessoal e seu equivalente pronome possessivo são pouco usados. Nomes próprios, cargos ou títulos são usados em seu lugar. Assim, usa-se a função social -sensei, professor, ficando Tanaka sensei no.

d. A "casa" é do professor, e a relação é [professor >aluno]

Na forma plana, a frase seria: (3) Watashi(wa) ${ }^{8}$ Tanaka sensei(no) uchi (e) iku. Usando os honoríficos ficaria: (4) Watakushi(wa) Tanakasensei (no) otaku(e)mairu. Acrescentando a "polidez" ficaria: (5) Watakushi(wa) Tanakasensei(no) otaku(e) mairimasu.

Explicando: a sentença (3) seria traduzida como: Vou à casa do professor Tanaka - pronome e verbos nas formas planas mais o sonkeigo, no substantivo Tanaka acrescido do título sensei (professor); na sentença (4), a tradução é a mesma, no entanto, há aqui a presença do honorífico de humildade, o kenjôgo, no pronome watakushi (eu) e no verbo mairu (ir) e o honorífico de respeito, o sonkeigo, no substantivo Tanaka acrescido do título sensei (professor) e no substantivo otaku (sua casa); na sentença (5), além das expressões do item 4, temos ainda o verbo mairu (ir) conjugado com a terminação - masu.

No (3) o verbo $i k u$ ainda pode ser conjugado e receber a terminação - masu, ficando ikimasu, que é a forma verbal como o aluno de Japonês como Língua Estrangeira é introduzido à língua.

Outro item também importante no ato de fala é a presença dos verbos de benefício. Eles são usados principalmente nas expressões de tratamento, keigo, como verbos auxiliares e expressam sentimento de gratidão e reconhecimento pelo ato de ter sido beneficiado. Vejamos:

\footnotetext{
6. O poder do aluno é menor do que o do professor.

7. O poder do professor é maior do que o do professor.

8. (wa)-A fim de facilitar a compreensão, neste trabalho, as partículas foram colocadas entre parênteses. $(\mathrm{Wa})$ é a partícula de tópico, (no) partícula do genitivo e (e) partícula equivalente ao "para, a", indicando direção.
} 
(7) Jikan (o) henkô shite itadakemasenka. (Não poderia alterar o horário?) a $\mathrm{b}$ c

a. Jikan $(o)^{9}-$ o horário

b. Henkô shite - alterar

c. Itadakemasenka. (itadaku - honorífico de humildade-receber, verbo de benefício)

Temos aqui itadak (raiz) $+e$ (sufixo de potencialidade) + masen (negativo da terminação de "polidez" - masu) + $k a$ (terminação indicativa de interrogativa)

Na língua japonesa, estes verbos de benefício são utilizados frequentemente exigindo do estudante de JL2 a analisar o contexto e usá-los de maneira adequada.

\section{A pesquisa e a metodologia}

\subsection{Metodologia}

Baseando nos estudos de expressões de tratamento de Takiura (2005) e Suzuki(1995) e na teoria de polidez de Brown e Levinson (1987), a pesquisadora fez um levantamento da polidez em três situações no ato de fala da língua japonesa aplicando o DCT (Discourse Completion Test) desenvolvido por Blum-Kulka (1982) e adaptado por Dias (2010), em falantes nativos, funcionários de empresas japonesas e representantes do governo japonês em Curitiba, na faixa etária de 20 a 35 anos, que estão no Brasil há menos de 3 anos. O teste foi traduzido para o português e aplicado a falantes brasileiros com faixa etária e perfis semelhantes. A partir das relações hierárquicas e sociais existentes nas expressões de tratamento da língua japonesa, a pesquisa visa verificar se o uso da polidez é realmente mais frequente nessa língua do que na língua portuguesa falada em Curitiba, ou se existem paralelos nos recursos de polidez das duas línguas. Por se tratar de estudo piloto, os dados ainda estão incompletos.

Para a análise preliminar, foram considerados os tipos de pedidos, a relação de poder entre os interlocutores, a distância e a relação social existentes.

O questionário apresentado foi o seguinte:

9. (o) - partícula que indica objeto direto. 


\section{Situação 1 - No aeroporto de Curitiba}

Você é um vendedor e tem um encontro marcado em São Paulo com o comprador de uma empresa às 11 horas, mas devido ao mau tempo em Curitiba, o avião das 7 horas não pôde levantar voo. Já são 8 horas e não há perspectiva de voo. Você deve tentar transferir, por telefone, o encontro para mais tarde do mesmo dia. Você diz: ...

Na situação1, a relação entre vendedor x comprador (círculo externo) deveria exigir um grau de formalidade maior visto que há uma relação de poder maior do interlocutor, assim como uma distância maior entre eles.

\section{Situação 2 - Na empresa}

Você quer ir a um casamento do irmão que vai se casar em Berlin e por isso deseja tirar uma semana de folga. Você precisa pedir permissão ao seu chefe para ausentar-se. Você diz ...

Já na situação dois, a relação é de hierarquia interna, sendo o interlocutor, o seu chefe direto, havendo uma distância considerável.

\section{Situação 3 - No happy hour}

Você está com os/as amigos/as do mesmo sexo num barzinho e está com pouco dinheiro. Você se sente meio constrangido/a, mas como esqueceu o cartão em casa, precisa pedir para que um/uma dos/as seus/suas amigos/as lhe pague a conta. Você diz:...

Na situação três, a relação é de amizade, sem distância.

\subsection{Métodos de análise}

Neste artigo, utilizaremos a unidade funcional baseada na "fórmula semântica" que foi usada para analisar o comportamento linguístico desenvolvido por Cohen, A.D.,\& Olshtain, E. aperfeiçoada por Adkoga, P. \& Obama , R. (2008) no artigo An analysis of the request behavior of Japanese and Turkish students: Exhibiting consideration for the interlocutor, apud Ishii (2010, p. 265) nos Anais do VIII Congresso Internacional de Estudos Japoneses no Brasil. A classificação será realizada pelos elementos que estruturam os comportamentos dos pedidos de acordo com esta "fórmula semântica". A seguir, apresentamos uma tabela contendo exemplos em japonês e português, baseados no que os falantes preencheram no questionário citado acima. 
Tabela 2 - Fórmula semântica

\begin{tabular}{|c|c|c|c|}
\hline & Classificação & Exemplo em japonês & Exemplo em português \\
\hline 01 & $\begin{array}{l}\text { Alertas }{ }^{10} \text { (pronome } \\
\text { de tratamento, } \\
\text { nome, marcadores } \\
\text { de fala) }\end{array}$ & $\begin{array}{l}\text { Osewa(ni) natteorimasu. } \\
\text { (Tradução literal - Estou em } \\
\text { débito com você!) É um } \\
\text { cumprimento, usado muito } \\
\text { quando se inicia um assunto } \\
\text { com fornecedor, colega, etc. }\end{array}$ & Senhor! \\
\hline 02 & $\begin{array}{l}\text { Anúncio preliminar } \\
\text { de pedido }\end{array}$ & $\begin{array}{l}\text { Taihen } \\
\text { môshiwakearimasenga. }{ }^{11} \\
\text { (Desculpe-me muito, mas ...) }\end{array}$ & Oi José, tem um minuto? \\
\hline 03 & $\begin{array}{l}\text { Pedido de } \\
\text { desculpas }\end{array}$ & $\begin{array}{l}\text { Môshiwakearimasen } \\
\text { (Desculpe-me) }\end{array}$ & Desculpe-me. \\
\hline 04 & $\begin{array}{l}\text { Explicando a } \\
\text { situação }\end{array}$ & $\begin{array}{l}\text { Hikôki(ga) kiri(no) tame } \\
\text { ririku dekinai jôtaidesu } \\
\text { (O avião não pode decolar } \\
\text { devido ao forte nevoeiro) }\end{array}$ & $\begin{array}{l}\text { O aeroporto aqui de } \\
\text { Curitiba está fechado } \\
\text { devido ao mau tempo... }\end{array}$ \\
\hline 05 & Pedido direto & $-\mathrm{x}-$ & ..me empresta quarentinha aí! \\
\hline 06 & $\begin{array}{l}\text { Pedido direto - } \\
\text { usando a forma } \\
\text { afirmativa ou a } \\
\text { interrogativa }\end{array}$ & $\begin{array}{l}\text { Genkin(ga) tarinainode } \\
\text { tatekaete morattemoii? } \\
\text { (como não tenho dinheiro } \\
\text { suficiente, você pode pagar } \\
\text { por mim?) }\end{array}$ & $\begin{array}{l}\text { Esqueci meu cartão. Alguém } \\
\text { me salva? }\end{array}$ \\
\hline 07 & Pedido indireto & $\begin{array}{l}\text { Môshiwakearimasenga, } \\
\text { honjitsu(no) kaigi(wo) } \\
\text { gogo(ni) henkô shite } \\
\text { itadakukoto(wa) } \\
\text { kanôdeshoka. (Desculpe-me, } \\
\text { mas seria possível transferir a } \\
\text { reunião de hoje para a tarde?) }\end{array}$ & $\begin{array}{l}\text {...gostaria de remarcar nossa } \\
\text { reunião para o período da } \\
\text { tarde, isso é possível? }\end{array}$ \\
\hline 08 & $\begin{array}{l}\text { Garantia de que } \\
\text { não vai prejudicar }\end{array}$ & $\begin{array}{l}\text { Heiin fuzaich } \hat{u}(\text { no) gyômu } \\
\text { hikitsuzukinado(wa), } \\
\text { irounakiyou taiôsuruyô(ni) } \\
\text { itashimasu. (Durante a minha } \\
\text { ausência, deixarei as minhas } \\
\text { atribuições para os colegas } \\
\text { de forma que não haja prejuízo } \\
\text { no andamento do trabalho) }\end{array}$ & $\begin{array}{l}\text { Vou me organizar com a } \\
\text { equipe para deixar o } \\
\text { trabalho esquematizado! }\end{array}$ \\
\hline
\end{tabular}

10. Usado para chamar a atenção do interlocutor.

11. Esta expressão é muito utilizada para anunciar um pedido. "Desculpar-se" em língua japonesa é quase uma convenção para iniciar um pedido no ato de fala. 


\begin{tabular}{|ll|l|l|}
\hline 08 & Aliviar a carga & $\begin{array}{l}\text { Moshi kanôde areba } \\
\text { (se for possível...) }\end{array}$ & Seria possível ... \\
\hline 09 & Louvar o outro & -x- & -x- \\
\hline 10 & $\begin{array}{l}\text { Colocar a sua } \\
\text { incapacidade como } \\
\text { motivo. }\end{array}$ & $-\mathrm{x}-$ & $-\mathrm{x}-$ \\
\hline 11 & Agradecimento & Môshiwakenai ${ }^{12}$ & Valeu! Muito obrigado. \\
\hline
\end{tabular}

\section{Análise e observações}

\subsection{Situação um - No aeroporto}

Tanto os falantes japoneses como os brasileiros se utilizaram das estratégias de dar explicações, fazer anúncio preliminar ou se desculpar para iniciar o pedido. No entanto, observou-se que todos os seis entrevistados japoneses utilizaram a estratégia da desculpa - taihen môshiwake arimasen, sumimasen. Dois deles repetem duas vezes durante o pedido, enquanto apenas dois brasileiros pediram desculpas. Pedir desculpas é um ato muito comum na sociedade japonesa. Existem várias formas e graus de pedidos de desculpas. No dia a dia, eles utilizam a forma - sumimasen e suas variantes e - môshiwake arimasen nos casos mais formais. Segundo Brown e Levinson (1987, p. 187), ao pedir desculpas, o falante expressa o desejo de não se impor sobre a face negativa do ouvinte, reparando parcialmente tal imposição. Outras estratégias como admitir a imposição ou pedir permissão são considerados "desarmadores" por Blum e Kulka (1982) que ao optar por elas, o falante deixa a face positiva vulnerável e ao rebaixar-se, demonstra consideração pela face negativa do ouvinte. Como foi dito anteriormente, na língua japonesa, nos relacionamentos entre vendedor e comprador, que pertencem a círculos diferentes, o honorífico de modéstia é usado para demonstrar respeito, o que leva a preservar a face do ouvinte.

No caso do japonês, outra característica marcante é o uso dos honoríficos seguido da expressão de "polidez" e do verbo de benefício.

"Honjitsu(no) kaigi(wo) gogo(ni) henkô shite itadaku koto(wa) kanô deshô$k a . "$ (Será que é possível transferir a reunião de hoje para a tarde?). O verbo henkô shite itadaku é composto do verbo henko suru, alterar + itadaku,verbo de benefício, ou seja, o falante deseja "receber o benefício de ter o horário alterado", além do uso do - deshôka, equivalente ao "será que" do português. As frases negativas

12. Significa literalmente "desculpe-me", mas no contexto usado o significado é de "obrigado" 
interrogativas, representantes máximas da polidez negativa, estão presentes em todos os que responderam ao questionário, demonstrando com isso que o relacionamento com o círculo externo exige do falante maior uso de honoríficos e polidez tanto no enunciado como na enunciação.

O mesmo pode-se dizer dos falantes de português. Das três situações apresentadas, esta foi a que eles mais usaram as estratégias de polidez. O que difere das colocações dos japoneses é que o brasileiro tem como costume iniciar o discurso, chamando o interlocutor pelo nome, ou pelo uso do pronome de tratamento mais o nome, como em: "Alô! Bom dia Sr. Carlos!" ou "Oi Thiago,...", demonstrando com isso maior aproximação e intimidade. O uso do termo impessoal "é possível" aparece três vezes e o verbo "poder" na primeira pessoa do plural no presente do indicativo também na mesma quantidade indicando maior diretividade do que se usassem o verbo na condicional. Esta só aparece uma vez em "... gostaria de remarcar nossa reunião..." Ao usar a primeira pessoal do plural, o brasileiro tende a preservar mais a sua face positiva do que se usasse a condicional, o que difere muito do ato de fala dos falantes de japonês.

\subsection{Situação dois - Na empresa}

Esta situação, em que a hierarquia vertical está presente, notamos que os falantes de japonês usaram a expressão - "kyûka(wo) itadakenaideshôka?" (Será que não poderia tirar férias?) e suas variantes com significados semelhantes, solicitando permissão ao seu chefe para ir ao casamento do irmão.

Por outro lado, os brasileiros expressam a necessidade de ir ao casamento e perguntam se é possível, ou se está tudo bem, como no exemplo abaixo.

"Oi José, tem um minuto? Bom, meu irmão vai se casar daqui a 3 meses em Berlim! Vou me organizar com a equipe para deixar o trabalho esquematizado! Penso em ficar 15 dias na Alemanha, tudo bem?"

Nas sentenças apresentadas por eles, percebe-se que há mais uma comunicação de que vão se ausentar devido à necessidade de ir a um compromisso importante do que um pedido de permissão como nos falantes de japonês.

"Jitsu(wa) raigetsu, berurin(ni) iru watashi(no) otôto(ga) kekkon suru tame, moshi kanôde areba isshûkan kyûka(wo) itadakenai deshôka." (Como o meu irmão vai ser casar em Berlin no mês que vem, se possível, será que não poderia (receber o benefício de) tirar uma semana de folga?)

Talvez seja um costume das empresas brasileiras, mas dos seis que responderam ao questionário, quatro apresentaram trabalho esquematizado durante a ausência. Um se compromete fazer horas extras para compensar e apenas um que pede formalmente permissão para férias não apresenta nenhum esquema ou compensação. No caso dos japoneses, apenas um deles se mostrou preocupado 
em repassar os serviços para os colegas e se comprometeu a não prejudicar o andamento do trabalho durante sua ausência. Ele faz essa colocação com muita deferência, utilizando o honorífico de humildade - "Heiin fuzaichû(no) gyômu hikitsuzukinado(wa), irounakiyou taiôsuruyô(ni) itashimasu." (Durante a minha ausência, deixarei as minhas atribuições para os colegas de forma que não haja prejuízo no andamento do trabalho). Das três situações apresentadas, esta foi a que houve maior diferença na colocação do pedido.

\subsection{Situação 3 - No happy hour}

Todos os que responderam ao questionário usaram as mesmas estratégias: explicação do motivo, garantia de que não iria prejudicar o interlocutor e pedido direto seguido de interrogativa para amenizar a situação. Três falantes japoneses começam o pedido, usando a expressão gomen (desculpa - forma informal). Convém ressaltar que esse termo, neste contexto, não tem apenas o significado de pedido de desculpas, mas sim também de "por favor". Outra característica nos pedidos feitos por eles é a presença da expressão warui(no) dakeredo [é ruim/chato (pedir isso) mas...] e suas variantes ${ }^{13}$ antes de fazer o pedido de empréstimo. Ele é um anúncio preliminar de pedido.

No caso dos falantes brasileiros, notamos a presença de palavrões no início da oração usados para mostrar a indignação com o fato de ter esquecido a carteira, e pedidos diretos de empréstimo como em "me empresta quarentinha aí!".

Também o agradecimento "valeu", "muito obrigado" aparece com maior frequência entre os brasileiros. Em apenas uma situação, o falante japonês agradece usando a expressão môshiwakenai (vide nota de rodapé 13) em todos os questionários analisados.

O que chamou atenção também é a presença de "pode" e "tem como" para pagar a conta, entre os brasileiros, demonstrando que o favor é maior mesmo com os amigos nesta situação do que naquela em que é necessário pedir ao chefe uma semana de férias.

\section{7. considerações finais}

O questionário-piloto proporcionou observar muitas questões sobre o ato de fala. Uma das principais é a questão hierárquica. No Brasil, ela é menos considerada do que na sociedade nipônica, em que ela sempre esteve presente. Em geral, nota-se que os brasileiros tendem a preservar mais a sua face positiva. No contexto em

13. Como as expressões usadas neste contexto são informais, encontramos ainda wariindakedo e waruindakedo. 
que eles precisam reagendar a reunião, eles explicam o motivo do atraso e usam o pronome na primeira pessoa do plural - "podemos alterar o horário?" preservando a sua face positiva, enquanto os japoneses utilizam estratégias em que a face negativa é mais acentuada, como em "Kono shittai(wo) okashi, taihen môshiwake gozaimasen. Moshi yoroshikereba, honjitsu gogo aratamete ukagaitaino desuga, gotsugô ikagadeshôka." (Muitas desculpas por ter causado tanto transtorno. Se for de seu agrado, gostaria de fazer uma visita hoje à tarde. Como será que estaria a sua agenda?) O pedido de desculpas, que é quase institucionalizado, acrescido de uso constante da condicional e expressões de humildade, preservando a face do interlocutor, é característico dos pedidos para alguém do círculo externo.

Nas situações apresentadas, constatamos que tanto numa língua como na outra, a polidez está presente em maior ou menor grau com estratégias diferentes. No entanto, devido aos inúmeros recursos de expressões de tratamento em japonês, os pedidos da língua japonesa em geral são mais formais e mais indiretos do que o português brasileiro. As estratégias são diversas, mostrando as diferenças socioculturais que necessitam ser estudadas com maior cuidado na dissertação para que elas sirvam de base para uma abordagem mais eficiente no ensino das expressões de tratamento do japonês para os aprendizes brasileiros de JL2.

As observações aqui apresentadas são ainda preliminares e merecem maior análise no decorrer da pesquisa que deve ocorrer durante o ano de $2013 \mathrm{com}$ um questionário mais detalhado para um número maior de pessoas.

\section{Referências bibliográficas}

BROWN, Penelope and LEVINSON, Stephen. Politeness: Some universals in language, Cambridge University Press, 1987.

BUNKACHÔ - BUNKASHINGIKAI KOKUGOBUNKAKAI. Keigo no shishin). Tóquio:2007. Disponível em http://www.hunka.go.jp/1kokugo/pdf/kokugo_bunkakai190115_siryou2. pdf. acesso em 30.11.2012.

CHINAMI, Kyouko. Nihongono Poraitonesu - sono seido sokumen to goyôron sokumen. In Kannichi gengo bunka kenkyuu, ${ }^{\circ}$ 6, 2005, p. 35-66. Disponível em https:/qir.kyushuu.ac.jp/dspace/bitstream/2324/16838/32/p050.pdf.txt, acesso em 20.05.2010.

COHEN,Andrew\&OLSHTAIN, Elite. Developing a measure of socio-cultural competence: "The case of apology". In: Language Learning, 31, the Language Learning Research Club at the University of Michigan, 1981, p. 113-134.

DIAS, Luzia S. Estratégia de Polidez Linguística na Formulação de pedidos e ordens contextualizados: um estudo constrativo entre o português curitibano e espanhol montevideano. Curitiba: Tese (doutorado em Linguística) Universidade Federal do Paraná, 2010 Disponível em http://dspace.c3sl.ufpr.br/dspace/bitstream/handle/1884/24943/ TESE_EST.PDF, acesso em 16.11.2011. 
GOFFMAN, Erving. Interaction Ritual: essays on face-to-face behavior. New York: Doubleday Anchor, 1967.

GRICE, Paul. Lógica e Conversação. In: DASCAL, Marcelo (ed.). Fundamentos metodológicos da lingüística: problemas, críticas, perspectivas da linguística. Tradução: João Wanderlei Geraldi. São Paulo: UNICAMP, p. 81-103, 1982 [1975].

IDE, Sachiko. Wakimae no goyouron. Tokyo: Taishûkan Shoten, 2006.

IORI, Isao. et alii. Nihongo Bunpô Handbook. Tóquio: 3A Corporation, 2000.

ISHII, Miwako. 'Irai' hyougen ni okeru taishô goyôron kenkyû - nihongo washato supeingo bogowashano baai. In: Congresso Internacional de Estudos Japoneses no Brasil, 8, 2010. Brasília, Anais... Brasília, 2010, p. 263-268.

KIKUCHI, Wataru. Sociedade japonesa: base estrutural das relações sociais. In Estudos Japoneses. $\mathrm{N}^{\mathrm{o}}$ 24, 2004, p. 107-124.

Taigû hyôgen. In MATSUBARA, Leiko (org.). Tópicos de Gramática da Língua Japonesa. São Paulo: Fundação Japão, 2011. Capítulo 9, 197-217.

LEVINSON, Stephen. Pragmática. 1ª ed. São Paulo: Martins Fontes, 2007.

MATSUMOTO, Yoshiko. (1988): Reexamination of the universality of face: Politeness Phenomena in Japanese. Journal of Pragmatics, t 12, pp. 403-426.

SUZUKI, Tae. As Expressões de Tratamento da Língua Japonesa. São Paulo: Editora da Universidade de São Paulo, 1995.

TAKIURA, Masato. Nihon no keigoron. Tóquio: Taishûskanshoten, 2005. 